\title{
Investigating non-response bias in mail surveys
}

\author{
K. SHEIKH* \\ From the MRC Epidemiology and Medical Care Unit, Harrow \\ S. MATTINGLY \\ From the Garston Manor Rehabilitation Centre, Hertfordshire
}

SUMMARY Losses in follow-up that are biased with respect to outcome invalidate the results. There are many ways of dealing with non-response in follow-up studies. Three separate methods were used to investigate a potential bias in a mail survey of 2471 disabled people. At a response rate of $84 \%$, the non-respondents were significantly different from the respondents with respect to the outcome, return to work and vocational training. The success rate in terms of the outcome was negatively related to the number of reminders. Significant differences were found in response rates according to age, social class, impairments, previous employment record, and completion of rehabilitation courses. There is no safe level of response rates below $100 \%$. However small the non-response, a possible bias as a result of it must be investigated.

In spite of all the forethought and persistence put into follow-up, there are almost always some unco-operative individuals who fail to respond. Whatever the cause, non-respondents may not be a random subgroup, that is, the respondents may not be representative of the parent population. However small the non-response, a possible bias as a result of the lost information has to be investigated and its extent estimated.

Depending on the type of follow-up and the nature of the study, there are many ways of dealing with non-response. ${ }^{1-8}$ Ideally, a separate investigation should be carried out on all, or a representative subsample of, non-respondents. Alternatively, the required information about non-respondents may be obtained by an indirect method, that is, from other sources. This, however, is not always possible. Two methods of estimating non-response bias are commonly used in prospective studies. Firstly, the difference in outcome between early and late respondents may indicate non-response bias, and its extent may be proportional to the delay in response. In many studies, the event under investigation has been found to occur more frequently in the last batch of responses (for example, questionnaires returned) than in early responses. ${ }^{1}$ On the basis of such a linear or curvilinear relationship between the delay in response and the frequency of outcome, it may be possible to predict the outcome in non-respondents.

-Present address: Department of Epidemiology, University of Michigan School of Public Health, 109 Observatory Street, Ann Arbor, Michigan 48109, USA.
The second method makes use of population characteristics. For example the , difference between respondents and non-respondents in terms of age, sex, and social class may indicate non-response bias. In these methods, certain assumptions are made. In the former, response behaviour is assumed to be a function of the outcome; in the latter, demographic or other basic characteristics are assumed to be causally related to the outcome.

This paper illustrates an example of a follow-up study in which potential non-response bias was shown by each of the methods of investigation.

\section{Methods}

Three groups of economically active disabled people potentially suitable for open employment were followed to study the outcome of rehabilitation in terms of return to work: 358 patients were discharged from Garston Manor Medical Rehabilitation Centre (MRC) in 1973-5, 1050 from Garston Manor Employment Rehabilitation Centre (ERC) in 1973-5 and 1063 from Perivale ERC in 1975-6. Details of demographic characteristics, medical and employment histories, and psychological and functional assessments were obtained from the case-notes at the centres. Occupational psychologists at the centres used standard tests to assess the intelligence and motivation for work of the rehabilitees.

The importance of follow-up was explained to the 93 
to inform the centres about any change in their postal addresses. Prepaid postcards were supplied for this purpose. A register of their addresses was maintained, and those who moved without giving a new address were traced by the methods described by Laurence. ${ }^{8}$ Those who could not be traced after an extensive search were excluded from follow-up even though some information about their employment status was known. Others excluded were those who died and those who left the United Kingdom to work abroad.

A self-administered postal questionnaire was sent to each member of the three groups six months and one year after discharge. At each follow-up, the questionnaire inquired in confidence about employment, vocational training, and the reasons for unemployment where applicable. (Copies of the questionnaire are available on request). A brief personal covering letter, a prepaid reply envelope, and a prepaid postcard for subsequent change of address were enclosed with each questionnaire. Up to four postal reminders were sent at monthly intervals. Each reminder was accompanied by an additional questionnaire and a prepaid reply envelope. Outgoing and return postage was paid at second class rate.

For those subjects who failed to respond, even after reminders, information about employment and/or vocational training was obtained from other sources; these included disablement resettlement officers (DROs), employment offices, general practitioners, hospital physicians, social workers, employers, and relatives. As far as possible, all information about employment, whether from the subjects or from other sources, was examined for accuracy by internal (within questionnaire) cross-check or against information received from different sources during previous or subsequent inquiries. Incomplete questionnaires were returned to the addressees who were requested to answer all the questions.

The $\chi^{2}$ test $^{9}$ was used to test the significance of differences between linear trends in respondents and non-respondents.

\section{Results}

Of the total population of 2471,62 were lost at the six-month follow-up. Of the remaining 2409 who were sent the first questionnaires, 2020 (83.9\%) returned them completed; information about employment and training was obtained from other sources for $360(14.9 \%)$, and the outcome at six months was not known for $29(1 \cdot 2 \%)$.

A further 53 individuals were lost to the one-year follow-up and were therefore excluded. Of the total of 115 exclusions, about a third had died, a third had left the country, and the remaining third could not be traced. Table 1 shows the response from the three groups who were available for the one-year follow-up. Of the 2356 subjects who were sent the second questionnaires, $1749(74 \cdot 2 \%)$ returned them completed; information about employment and training was obtained from other sources (mainly DROs and general practitioners) for $550(23.4 \%)$, and the outcome at one year was not known for 57 $(2 \cdot 4 \%)$. The differences and similarities between respondents and non-respondents were consistent in the three centres; the results were therefore combined.

Table 1 Results of one-year follow-up

\begin{tabular}{lrrrr}
\hline & \multicolumn{2}{c}{ NO. OF SUBJECTS BY CENTRE } & \\
\cline { 2 - 4 } & \multicolumn{2}{c}{ Garston Manor } & Perivale & TOTAL \\
\cline { 2 - 4 } & $M R C$ & ERC & ERC & \\
\hline Lost to follow-up & 21 & 40 & 54 & 115 \\
Respondents & 270 & 781 & 698 & 1749 \\
$\begin{array}{l}\text { Non-respondents: } \\
\text { Outcome known }\end{array}$ & 61 & 211 & 278 & 550 \\
$\begin{array}{l}\text { Outcome not known } \\
\text { TOTAL }\end{array}$ & 6 & 18 & 33 & 57 \\
\hline
\end{tabular}

DIFFERENCES IN OUTCOME

For the purpose of examining the differences in the outcome, the respondents were compared with those non-respondents whose outcome was known. During the follow-up period, 398 people had started to attend full-time vocational training courses; in terms of return to work, they could not be counted as unemployed or 'failures'. For them, therefore, the start of a training course was taken as the outcome and their response behaviour was compared with that of those subjects who were recommended for, but did not start, training.

Table 2 shows the employment status of the respondents and non-respondents for whom employment data were available (in all 2380 at six-month follow-up and 2299 at one-year follow-up), excluding the 398 trainees. At the time of each follow-up, a higher proportion of those who were employed than of those who were unemployed returned the questionnaires $(p<0 \cdot 01)$.

Table 2 Response according to employment status

\begin{tabular}{llrl}
\hline Follow-up & Status & $\begin{array}{l}\text { Total } \\
\text { No. }\end{array}$ & $\begin{array}{l}\text { Respondents } \\
\%\end{array}$ \\
\hline Six-month & Employed & 854 & 87.0 \\
& Unemployed & 1128 & 81.2 \\
One-year & All & 1982 & 83.7 \\
& Employed & 935 & 78.2 \\
& Unemployed & 966 & 73.0 \\
& All & 1901 & 75.5 \\
\hline
\end{tabular}


At the six-month follow-up, $74 \%$ of the 1659 respondents returned the first questionnaires sent to them, and the remaining $26 \%$ responded to reminders. At the one-year follow-up, $67 \%$ of the 1436 respondents returned the initial questionnaires. Table 3 shows the relationship between the employment status and the delay in response. At the time of each follow-up, a higher proportion of the respondents who returned the initial questionnaires were employed than of those who had to be reminded, and a lower proportion of the respondents who returned the questionnaires after three to four reminders were employed than of those who responded after one to two reminders $(p<0 \cdot 05)$.

Table 3 Employment status in relation to the delay in response from 1659 respondents at six-month follow-up and 1436 at one-year follow-up

\begin{tabular}{lllll}
\hline & First & \multicolumn{4}{l}{ After reminders } \\
\cline { 3 - 5 } & inquiry & 1 & 2 & $3-4$ \\
\hline $\begin{array}{l}\text { At six months } \\
\text { No. of respondents }\end{array}$ & 1225 & 334 & 75 & 25 \\
Employed (\%) & 46.9 & 39.2 & 41.3 & 24.0 \\
$\begin{array}{l}\text { At one year } \\
\text { No. of respondents }\end{array}$ & 961 & 394 & 58 & \\
Employed (\%) & 53.6 & 45.9 & 48.3 & 47.8 \\
\hline
\end{tabular}

Of those who were recommended for training, a higher proportion of the ones who had started training returned the questionnaires at each follow-up than of those who had not started training $(\mathrm{p}<0.01)$.

\section{DIFFERENCES IN CHARACTERISTICS}

The age distribution of all the 2356 subjects who were followed for a year is given in Table 4. Higher proportions of older than of younger subjects returned the questionnaires $(\mathrm{p}<0 \cdot 001)$. Of the 2126 men, $73.9 \%$ responded, and of the 230 women, $77.4 \%$ responded; this sex difference was not statistically significant. The social class of 84 subjects was not known because they had never worked. Table 5 shows that among the 2272 who could be classified, a higher proportion of those in higher

Table 4 Response from 2356 subjects according to their age

\begin{tabular}{|c|c|c|c|c|}
\hline \multirow[b]{2}{*}{$\begin{array}{l}\text { Age } \\
\text { groups } \\
\text { (years) }\end{array}$} & \multirow[b]{2}{*}{$\begin{array}{l}\text { Subjects } \\
\text { No. }\end{array}$} & \multirow[b]{2}{*}{$\begin{array}{l}\text { Respondents } \\
\%\end{array}$} & \multicolumn{2}{|c|}{ Non-respondents } \\
\hline & & & $\begin{array}{l}\text { Outcome } \\
\text { known } \\
\%\end{array}$ & $\begin{array}{l}\text { Outcome } \\
\text { not known } \\
\%\end{array}$ \\
\hline $\begin{array}{l}15-24 \\
25-34 \\
35-44 \\
45-54 \\
55.64\end{array}$ & $\begin{array}{l}545 \\
559 \\
506 \\
578 \\
168\end{array}$ & $\begin{array}{l}69.4 \\
71.0 \\
74.5 \\
79.6 \\
81.5\end{array}$ & $\begin{array}{l}27 \cdot 0 \\
26 \cdot 7 \\
23 \cdot 1 \\
18 \cdot 7 \\
17 \cdot 3\end{array}$ & $\begin{array}{l}3.6 \\
2.3 \\
2.4 \\
1.7 \\
1.2\end{array}$ \\
\hline
\end{tabular}

social classes than of those in lower classes returned the questionnaires $(p<0.05)$.

Previous employment record, that is, the number of jobs held in five years before admission to the rehabilitation centres, was known for 2051 subjects. A higher proportion of those who held fewer jobs than of those who held several jobs returned the questionnaires $(p<0.001)$. The distribution of impairments in the 2356 rehabilitated people is given in Table 6. A higher proportion of those with neurological impairments leading to motor deficit and a lower proportion of those with a history of psychoses or addiction than of the rest of the rehabilitated people returned the questionnaires.

Table 5 Response from 2272 subjects according to their social class

\begin{tabular}{|c|c|c|c|c|}
\hline \multirow[b]{2}{*}{$\begin{array}{l}\text { Social } \\
\text { Class }\end{array}$} & \multirow[b]{2}{*}{$\begin{array}{l}\text { Subjects } \\
\text { No. }\end{array}$} & \multirow[b]{2}{*}{$\begin{array}{l}\text { Respondents } \\
\%\end{array}$} & \multicolumn{2}{|c|}{ Non-respondents } \\
\hline & & & $\begin{array}{l}\text { Outcome } \\
\text { known } \\
\%\end{array}$ & $\begin{array}{l}\text { Outcome } \\
\text { not known } \\
\%\end{array}$ \\
\hline $\begin{array}{l}\text { I-II } \\
\text { III } \\
\text { IV } \\
\text { V }\end{array}$ & $\begin{array}{r}164 \\
1236 \\
601 \\
271\end{array}$ & $\begin{array}{l}81 \cdot 7 \\
74 \cdot 5 \\
75 \cdot 1 \\
68 \cdot 3\end{array}$ & $\begin{array}{l}17 \cdot 7 \\
23 \cdot 1 \\
22 \cdot 1 \\
28 \cdot 8\end{array}$ & $\begin{array}{l}0.6 \\
2.4 \\
2.8 \\
2.9\end{array}$ \\
\hline
\end{tabular}

Table 6 Response by impairments in 2356 subjects

\begin{tabular}{lll}
\hline Impairments & $\begin{array}{l}\text { Total } \\
\text { No. }\end{array}$ & $\begin{array}{l}\text { Respondents } \\
\%\end{array}$ \\
\hline Limb injuries & 360 & 73.3 \\
Backache & 325 & 76.0 \\
Neurological with motor deficit & 280 & 83.2 \\
Other neurological & 288 & 73.3 \\
Rheumatological & 183 & 78.7 \\
Cardiovascular and respiratory & 272 & 75.7 \\
Other organic & 86 & 74.4 \\
Psychoneuroses & 210 & 74.8 \\
Psychoses and addiction & 314 & 63.4 \\
None & 38 & 63.2 \\
\hline
\end{tabular}

Of the 2019 people discharged from the two ERCs, 1659 had completed the rehabilitation courses and 360 were discharged prematurely. Of those who completed the course, $75 \cdot 2 \%$ returned the questionnaires, but only $64.4 \%$ of those prematurely discharged did so. This difference was statistically significant $(\mathrm{p}<0.001)$.

There were no significant differences between the respondents and the non-respondents in terms of education, intelligence, motivation for work, duration of unemployment before rehabilitation, or duration of disability.

\section{Discussion}

While some authorities insist on limiting the non-response rate to $5 \%,{ }^{10}$ others would recommend a maximum of $20 \% .^{411}$ In practice, 
however, conclusions are often based on data obtained from less than $80 \%$ of the population followed. Clearly, an 'acceptable' or 'conventional' level of response cannot be generalised. Depending on the nature of the study and the event under investigation, even a small amount of bias may distort the results. However, the extent of bias need not necessarily be proportional to the non-response rate. ${ }^{12}$ The example illustrated in this paper clearly demonstrates that in spite of a response rate of $84 \%$ at six-month follow-up, the non-respondents were significantly different from the respondents with respect to return to work (Table 2) and training. These findings in a sense validate other methods used to investigate non-response bias, that is, the comparison of outcome in early and late respondents, and the comparison of non-respondents with respondents in terms of personal characteristics.

The results of this study support the phenomenon described by Hill. ${ }^{7}$ Unemployment was more prevalent in late respondents than in immediate respondents (Table 3); thus, response behaviour did appear to be influenced by the outcome. Late respondents were, in effect, reluctant to reveal their failure to achieve what was expected of them. They obviously underestimated the value of their response. Initially, they might have thought that the investigators would be interested only in 'successes'; repeated reminders, perhaps, persuaded them to change their opinions and behaviour. Those who could not complete the ERC courses may also have been inhibited from responding due to a sense of non-accomplishment.

Apart from differences in age, sex, and social class, the non-respondents differed from the respondents in terms of their previous employment record which probably reflected maladjustment and irresponsible behaviour. The results also suggest that psychiatric and personality disorders were probably responsible for a comparatively low response rate in the subgroup with a history of psychoses or addiction (Table 6). On the other hand, severe physical disability was probably a factor responsible for a relatively high response rate in those with motor deficit due to neurological impairments. Experience shows that patients who have something to complain about or report are more likely to respond to inquiries than those who have recovered from their impairments.

Reprints from Dr. K. Sheikh, Department of Epidemiology, University of Michigan School of Public Health, 109 Observatory Street, Ann Arbor, Michigan 48109, USA.

\section{References}

${ }^{1}$ Mainland D. Elementary medical statistics: Lost information. Philadelphia: WB Saunders, 1964: 178-86.

${ }^{2}$ MacMahon B, Pugh TE. Epidemiology: Principles and methods. Boston: Little Brown, 1970.

${ }^{3}$ Hill AB. Principles of medical statistics: Non-response. 9th edn. London: Lancet, 1971: 20-2.

${ }^{4}$ Meheus A. Response rate in prevalence studies. In: Holland WW, Karhausen L, eds. Health care and epidemiology. London: H. Kimpton, 1978: 105-6.

${ }^{5}$ Menotti $A$. Incidence in non-respondents. In: Holland WW, Karhausen L, eds. Health care and epidemiology. London: H. Kimpton, 1978: 133-4.

${ }^{6}$ Rumeau-Rouquette C. Non-response in case control studies. In: Holland WW, Karhausen L, eds. Health care and epidemiology. London: $\mathrm{H}$. Kimpton, 1978: 75.

${ }^{7}$ Hill AB. General principles of field surveys. In: Medical Research Council. The application of scientific methods to industrial and service medicine. London: HMSO, 1951: 16.

${ }^{8}$ Laurence KM. Tracing patients. Lancet 1959; ii: 208-12.

${ }^{\circ}$ Armitage P. Tests for linear trends in proportions and frequencies. Biometrics 1955; 11: 375-86.

${ }^{10}$ Doll R. Occupational factors in peptic ulcer. In: Medical Research Council. The application of scientific methods to industrial and service medicine. London: HMSO, 1951: 6.

${ }^{11}$ Rose G, Barker DJP. Epidemiology for the uninitiated: Conduct of surveys. Br Med J 1978; it: 1201-2.

${ }_{12}$ Cartwright A. Professionals as responders: variations in and effects of response rates to questionnaires, 1962-77. Br Med J 1978; it: 1419-21. 